\title{
INFLUENCE OF LAND USE / LAND COVER IN SIMULATING THE THUNDERSTORM EVENT USING MESOSCALE MODEL
}

\author{
D.V.Mahalakshmi ${ }^{2,3}$, P Sujatha ${ }^{1,2}$, K.V.S.Badarinath ${ }^{1}$, C.V.Naidu ${ }^{2}$

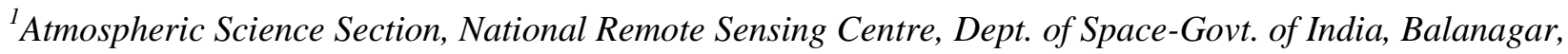 \\ Hyderabad, India \\ ${ }^{2}$ Department of Meteorology and Oceanography, Andhra University, Visakhapatnam \\ ${ }^{3}$ Regional Remote Sensing Centre-East, NRSC, ISRO, Newtown, Kolkata
}

\begin{abstract}
The effects of historical land use/land cover (LU/LC) changes on the convective activity over Hyderabad in pre monsoon season were investigated as a case study. The U. S. Geological Survey (USGS) LU/LC being used as default in mesoscale model which corresponds to 1992-93 period More over it was derived from AVHRR data (1 km resolution). LU/LC is one of the important governing parameters in mesoscale modeling. There is need to modify the LU/LC data in the model due to changes in LU/LC over long period of time and require higher spatial resolution. We have incorporated 2007-08 AWiFs (56m resolution) derived LU/LC data in mesoscale model to investigate whether it improves the simulation of thunderstorm activity over Hyderabad. In the present study, we made a comparative assessment of IRS-P6 AWiFS derived LULC data over Indian region with that of USGS in MM5 mesoscale model to simulate pre-monsoon season thunderstorm activity over Hyderabad on $13^{\text {th }} \& 17^{\text {th }}$ April 2006. The results of the study suggested that LU/LC has influence in simulate the convective activity. Further, the results suggest that it is proof of concept to show that LU/LC can be easily incorporated into MM5 for better understanding
\end{abstract}

Keywords: Mesoscale Model, Thunderstorms, land use/land cover

\section{INTRODUCTION}

Indian region in general experiences different type of weather systems like monsoon, tropical cyclones, heat waves and thunderstorms. Thunderstorms associated with heavy rainfall events are hazards to aviation Awedesh [1], crops and lives on the ground as well. Ghosh [2] furthermore, it has economic and societal impact on human existence. Earlier studies indicated that the important elements for monitoring severe local storm are thermal instability and vertical wind shear e.g., Brooks [3]; Craven [4]. Yamane and Hayashi [5] demonstrated that Convective Available Potential Energy (CAPE) represents the atmospheric instability required for the evaluation of environmental conditions for the formation of severe local storms over the Indian subcontinent. Many places over the Indian region experience thunderstorms at higher frequency during the pre-monsoon months (March-May), when the atmosphere is highly unstable due to high temperatures prevailing at lower levels. Different studies by Braham and Wilson [6], Shepherd and Burian [7], Niyogi [8] showed that urban land surface can influence local storm structure causing enhanced convection and increased precipitation. Previous studies have found that the urban heat island is an important feature in regional meteorology Oke, [9]. Gero and pitman [10] have found that local convective storms were highly sensitive to the triggering mechanism associated with land surface influences over the Australia's Sydney Basin. These severe thunderstorms are normally associated with lightning, torrential rain and hail cause extensive loss in agriculture, damage to property besides loss of life Tyagi, [11]. Topography, insolation, synoptically western disturbances and induced lows in the north, and easterly waves in south provide favorable conditions for the occurrence thunderstorm over these regions. Thunderstorms bring the first rain after a long dry and hot weather during pre monsoon season. The higher depth of moisture in the troposphere the higher is the potential for the formation of thunderstorm.

Numerical models must use higher spatial /temporal resolution data along with quality for better forecast purpose. Since forecast errors can arise from assumptions in physics parameterizations, model resolution limitations and land surface characteristics. In order to simulate atmospheric dynamics and thermodynamic processes adequately, mesoscale models require LU/LC dataset that accurately represents current environmental conditions as it effects the land-atmosphere interactions. Several research results showed that LU/LC affects the accuracy of the weather parameters Lam [12]; Daewon [13]. USGS derived LU/LC data that is currently being used in the fifth generation Mesoscale Model (MM5) corresponds 1992-93 time frame. USGS data contains 25-categories LULC features at different resolutions of 1-degree, 30, 10, 5, 2 minutes and 30 seconds. MM5/WRF mesoscale models use USGS generated regular latitude/longitude inputs on vegetation (LULC), terrain elevation, land-water mask, soil types, vegetation fraction and deep soil temperature. This results in over prediction of rainfall and other parameters, as there were considerable changes in agricultural activity over a period of time. Spatial details on LU/LC distribution was not properly addressed over the Indian region in USGS data 
sets as they were generated from $1 \mathrm{Km}$ resolution AVHRR data used for land use/land cover (LU/LC). The advent of multi-resolution satellite systems with high repetitively for natural resources monitoring made it possible to generate up to date information related to LU/LC over large region. In areas where afforestation took place, an average warming of more that $1{ }^{\circ} \mathrm{C}$ and in contrast, deforestation resulted in cooling of up to $2^{\circ} \mathrm{C}$ were observed by Nicolas and Werner [14].

\section{DATA AND MM5 MODEL DESIGN:}

MM5 used in the present study is a non-hydrostatic, terrainfollowing sigma co-ordinate model developed at National Center for Atmospheric Research (NCAR), USA (Dudhia [15]; Grell [16]. The model was configured with 23 vertical layers (with the model top at 100hpa). In this present study we used single domain with grid spacing of $6 \mathrm{~km}$. The simulations study herein was initialized at 00 UTC 12 April 2006 and integrated up to 00UTC of 14 April 2006 for simulating 13 April 2006 thunder event and 00 UTC of 16April2006 to 00UTC of 18 April 2006 for simulating 17 April 2006 thunder event Fig(a-d). The initial conditions and lateral boundary conditions for the model domain were taken from NCEP FNL data available at $1 \times 1$ degree resolution. This MM5 model sensitivity study was designed to compare effects of different land use data in meteorological simulations. Two sets of experiments were performed, first with the original USGS-LULC data sets and second with the AWiFS-LULC dataset over the Indian region. The details of the options used in this study are given in Table 1. The observations of rainfall from self recording rain gauge over Hyderabad were used in this study for model validation during the study period. The gridded rainfall data at $1^{0} \times 1^{0}$ resolution from Indian Meteorological Department (IMD) were used for analyzing spatial variation of rainfall Rajeevan [17].

Table1: Details of the model used in this study.

\begin{tabular}{|c|c|}
\hline Model & $\begin{array}{l}\text { Fifth generation Penn State } \\
\text { /NCAR Mesoscale Model } \\
\text { (MM5) }\end{array}$ \\
\hline Main prognostic variables : & $\begin{array}{l}\text { Non-hydrostatic with three- } \\
\text { dimensional Coriolis force }\end{array}$ \\
\hline Map projection & Mercator conformal mapping \\
\hline Central Point of Domain & $20^{\circ}$ North and $70^{\circ}$ East \\
\hline Horizontal grid distance & $6 \mathrm{~km}$ \\
\hline Number of vertical levels : & 23 half sigma levels \\
\hline Horizontal grid system & Arakawa B grid \\
\hline Time integration scheme & $\begin{array}{l}\text { Leap frog scheme with time- } \\
\text { splitting technique }\end{array}$ \\
\hline $\begin{array}{l}\text { Cumulus parameterization } \\
\text { scheme }\end{array}$ & Grell \\
\hline $\begin{array}{l}\text { Radiation parameterization } \\
\text { scheme }\end{array}$ & Cloud \\
\hline $\begin{array}{l}\text { PBL parameterization } \\
\text { scheme }\end{array}$ & MRF \\
\hline Microphysics & Simple Ice \\
\hline SoilModel & Multi-layer soil model \\
\hline $\begin{array}{l}\text { Land Use/Land Cover } \\
:\end{array}$ & USGS and AWiFS \\
\hline
\end{tabular}
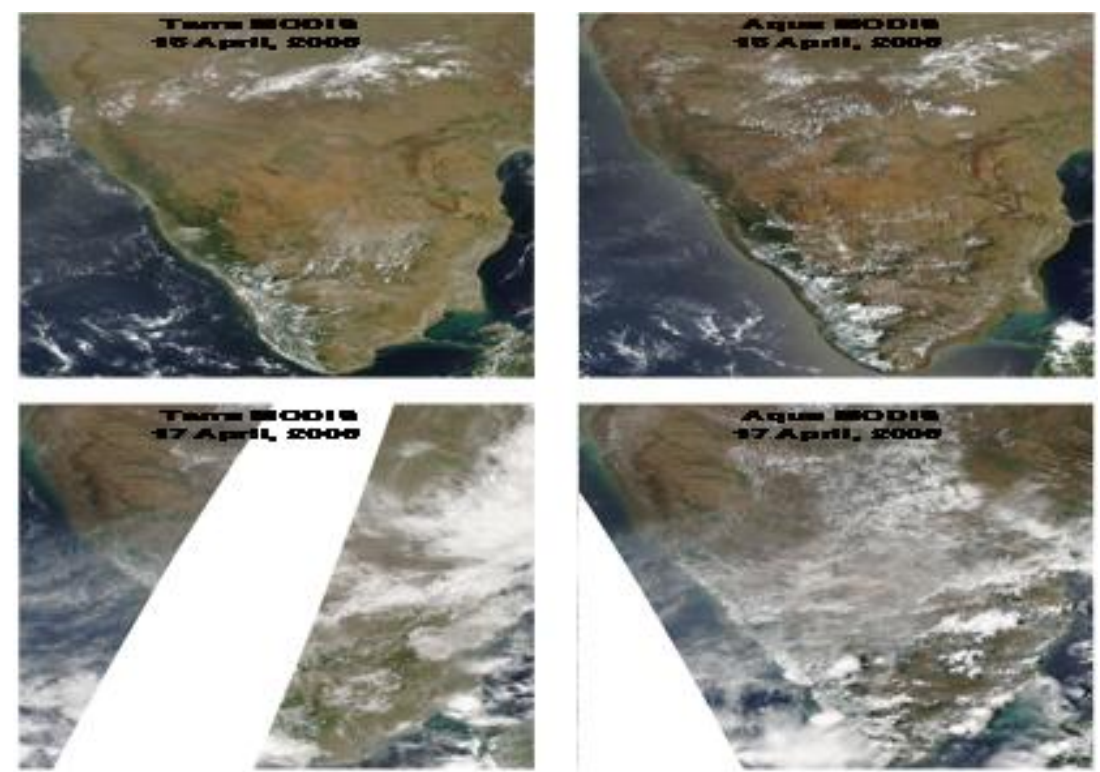

Fig - 1 (a-d): Terra/Aqua MODIS true color composites on

13 and 17 April 2006 showing intense cloud cover over Southern India.

2.1 Description of the AWiFS Land Use Data: 
Figure 1.(a, b) shows the land use/land cover(LU/LC) data from USGS and AWiFS .The changes in LU/LC details are due to year and resolution of satellite sensor as USGS data corresponds to 1992-93 and AWiFS data of 2007-08. USGS LU/LC data were derived from $1 \mathrm{~km}$ resolution of AVHRR data and AWiFS LU/LC data were generated at $56 \mathrm{~m}$ resolution. IRS-P6-Advance Wide Field Sensor (AWiFS)
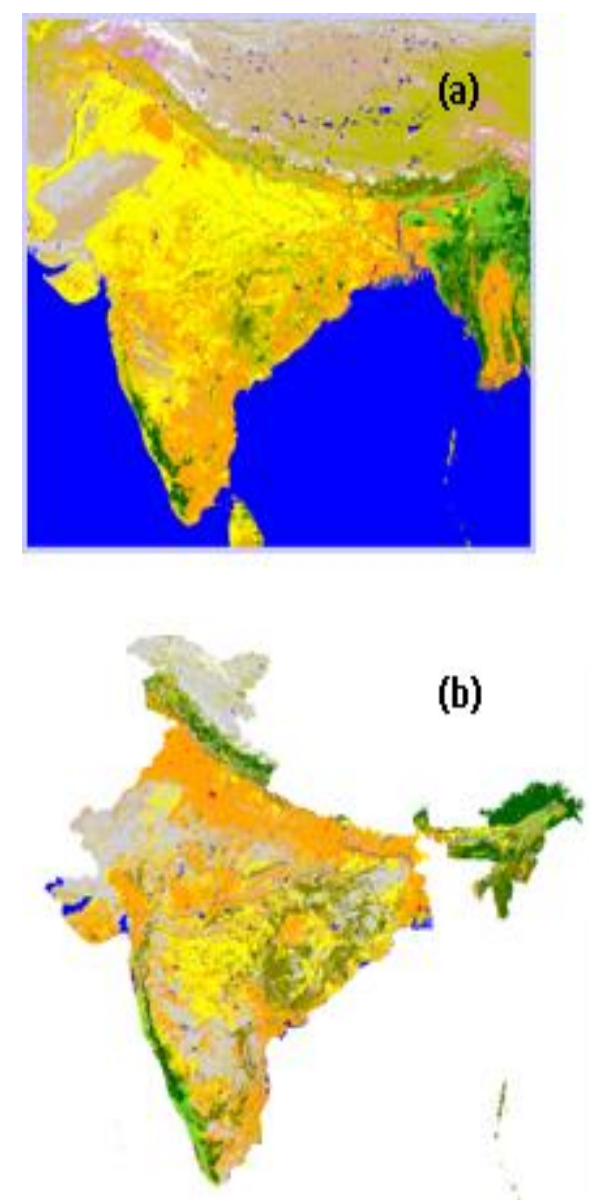

data was used to generate the LU/LC terrain data in order to compatible to MM5 model in different resolutions like USGS from digital classification technique.AWiFS camera with a spatial resolution of $56 \mathrm{~m}$ with 4 bands (green, red, near-infrared, and short-wave infrared) and covering swath of $740 \mathrm{~km}$ with a requisit time of approximately 5 days Badarinath[18].

Fig - 2: LU/LC maps over Indian region from (a) USGS (1992 - '93) and (b) AWiFS data sets (2007-'08)

Multi temporal IRS P6-AWiFS data covering different seasons were used to address spatial and temporal variability in cropping pattern and other land cover classes. These maps generated were field verified towards assessing classification accuracy.

Thunderstorms are more likely to develop in regions where the stability indices namely CAPE, Lifted Index, K Index and Total Totals Index have critical values as shown in Table 2. CAPE is a temperature inversion, which separates relatively warm temperatures above the boundary layer from the cooler boundary layer. The boundary layer generally warms during the day and becomes more buoyant or unstable. If sufficient warming occurs parcels are then sufficiently buoyant to rise to the Level of Free Convection (LFC), resulting in convection and possibly thunderstorms. In many cases dynamic forcing such as low-level convergence, low-level warm advection, or positive vorticity advection provide additional force to mechanically lift boundary layer parcels through the inversion. And another commonly used stability index is the Lifted Index (LI) which is based on a boundary layer air parcel lifted to $500 \mathrm{mb}$. The difference between the actual temperature and the parcel temperature is the Lifted Index.

Table2: Critical values of stability indices:

\begin{tabular}{|l|l|l|}
\hline Stability index & Description & Critical levels \\
\hline CAPE & $\begin{array}{l}\int \operatorname{LFCLNBg}(\theta \mathrm{vp}(\mathrm{z})- \\
\theta \mathrm{v}(\mathrm{z}) \mathrm{dz}(\mathrm{z})) / \theta \mathrm{v}\end{array}$ & $>1500$ \\
\hline Lifted Index & $\mathrm{T} 500-\mathrm{Tparcel}$ & $<-3$ \\
\hline K Index & $\begin{array}{l}\left(\mathrm{T}_{850^{-}}-\mathrm{T}_{500}\right)+\mathrm{DT}_{850^{-}} \\
\left(\mathrm{T}_{700^{-}}-\mathrm{DT}_{700}\right)\end{array}$ & $>33$ \\
\hline Total Totals & $\left(\mathrm{T}_{850^{-}} \mathrm{DT}_{850}\right)-2 \mathrm{~T}_{500}$ & $>44$ \\
\hline
\end{tabular}




\subsection{Meteorological conditions during April 2006}

Heat wave conditions prevailed over the various parts of the country up to second week of April, 2006. Trough or wind discontinuity at lower troposphere levels oscillating from West Madhya Pradesh to South Tamil Nadu resulted in enhancing moisture incursion during the third week of April 2006 (IMD portal). This moisture and vertical wind shear provided the necessary condition for the formation of thunderstorms on 13th and 17th April, 2006. The reported one day accumulated rainfall over Hyderabad on these days was $28 \mathrm{~mm}$ and $55 \mathrm{~mm}$ respectively. Figure- 1 (a-d) shows the Terra/Aqua MODIS true color satellite imagery over Indian region on 13 and 17 April, 2006 respectively. Intense cloud cover can be clearly seen from MODIS over Southern Indian region on 13 and 17 April, 2006 in order to confirming the convective activity over southern India.

We have examined different stability indices like CAPE, Lifted index, $\mathrm{K}$ index and Total totals index based on these two numerical simulations Doswell [19]. The spatial distribution of rainfall from both the simulations was compared with the Indian Meteorological Department (IMD) gridded rainfall data at $1^{0} \times 1^{0}$ resolutions for the Indian region. In addition, temporal variation of rainfall over Hyderabad site was compared with rain gauge measurements.

\section{RESULTS AND DISCUSSION:}

The interaction between surface and atmosphere plays a crucial role on development of convective cells and in turn cumulus convective rainfall. By keeping in this mind, we made an attempt to replace existing USGS-LU/LC with AWiFS LU/LC as discussed earlier. Vertical cross section of Relative humidity also has to be taken into account, as it is an essential factor for intense convection during Storm days Johns [20]. Figure 3(a-d) shows vertical cross section of relative humidity for 13 and 17 April, 2006 over Hyderabad from USGS and AWiFS MM5. It shows a considerable amount of moisture (more than $80 \%$ ) present at the lower and middle levels. Relative humidity remained high from the time of genesis of the thunderstorm to the time of precipitation. This is a favorable condition for thunderstorm formation. It can be concluded by examining the vertical distribution of relative humidity that there is enough moisture present in the lower and middle levels of the atmosphere during the thunderstorm period.

The general preconditions for initiation of thunderstorms are conditional instability, a sufficiently deep humid layer in the lower and mid troposphere and an uplifting mechanism to initiate convection.
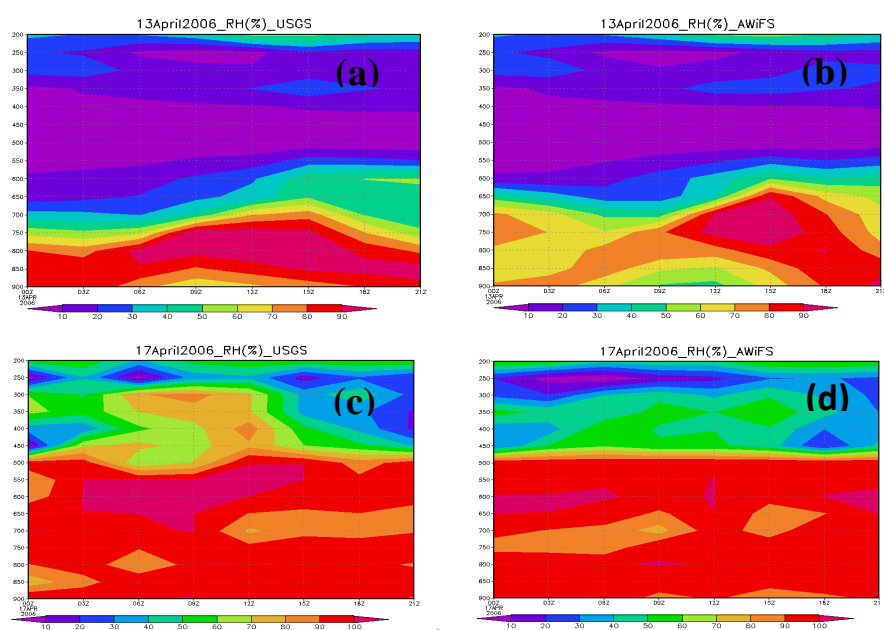

Fig -3 -3 (a-d): Vertical distribution of Relative Humidity (RH) (\%) over Hyderabad, India using MM5 USGS and AWiFS simulations on $13^{\text {th }}$ and $17^{\text {th }}$ April 2006 from 00UTC to 2100 UTC.

Fig. 4(a-d) shows time-height vertical velocity $(\mathrm{m} / \mathrm{sec})$ on 13th and 17th April, 2006 for USGS and AWiFS respectively. Downdraft in the lower parts of the thunderstorm spreads after the rainfall starts and it can be seen that changes in LU/LC pattern in MM5 causes considerable variations in vertical velocity. The simulation showed a direct response of meteorological conditions to the underlying surface features.

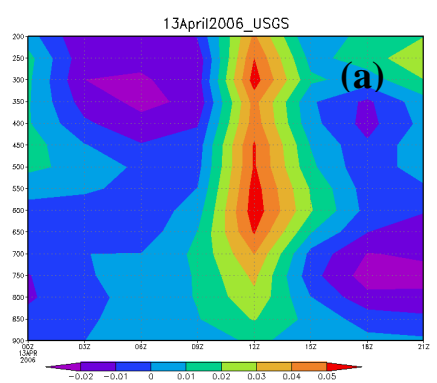

17April2006_USGS

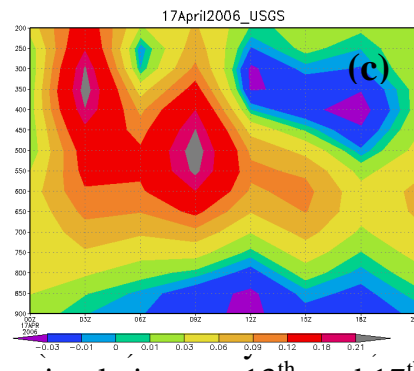

simulations on $13^{\text {th }}$ and $17^{\text {th }}$ April 2006 from 00UTC to 2100 UTC.

In this study, we have estimated the stability indices as shown in table 2 during thunderstorm activity. Figures $(5 \&$ $6)$ show the model simulated temporal variations of stability indices namely CAPE, LI, K-Index, total totals index on $13^{\text {th }}$ and $17^{\text {th }}$ April, 2006 respectively. The indices used in the present study are often found in the research literature as well and are helpful in predicting the severe weather events. As shown in table 2, based on the threshold value and above these threshold values, we can say that there is possibility of 
the severe convection. The model indices on $17^{\text {th }}$ April, 2006 using USGS and AWiFS LU/LC data suggest that model simulated well in capturing the thunderstorm event in both the cases as the synoptic flow patterns are strong. However, on $13^{\text {th }}$ April, 2006, synoptic flows were weak and MM5 model with AWiFS LULC data could simulate well in capturing the stability indices compared to MM5-USGS. The CAPE values on $13^{\text {th }}$ and $17^{\text {th }}$ April, 2006 ranging from 1500 to $3100 \mathrm{~J} / \mathrm{kg}$ (Fig5a) and 1950 to $2650 \mathrm{~J} / \mathrm{kg}$ (Fig6a) and the thermodynamic structure over Hyderabad became conducive for a thunderstorm occurrence.
The high value of CAPE (Fig5a\& 6a) at Hyderabad, considerable amount of humidity in the lower levels (Figs.3) and very sharp lapse rate were indicative of explosive instability and the consequent thunderstorm and rainfall. The results of the study indicate that not only stability indices but also humidity in lower levels plays a major role on storm activity.

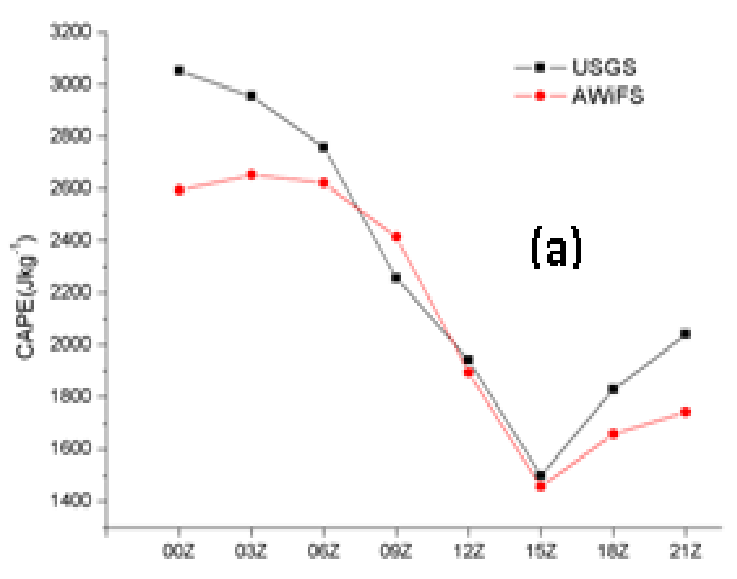

13 April, 2006
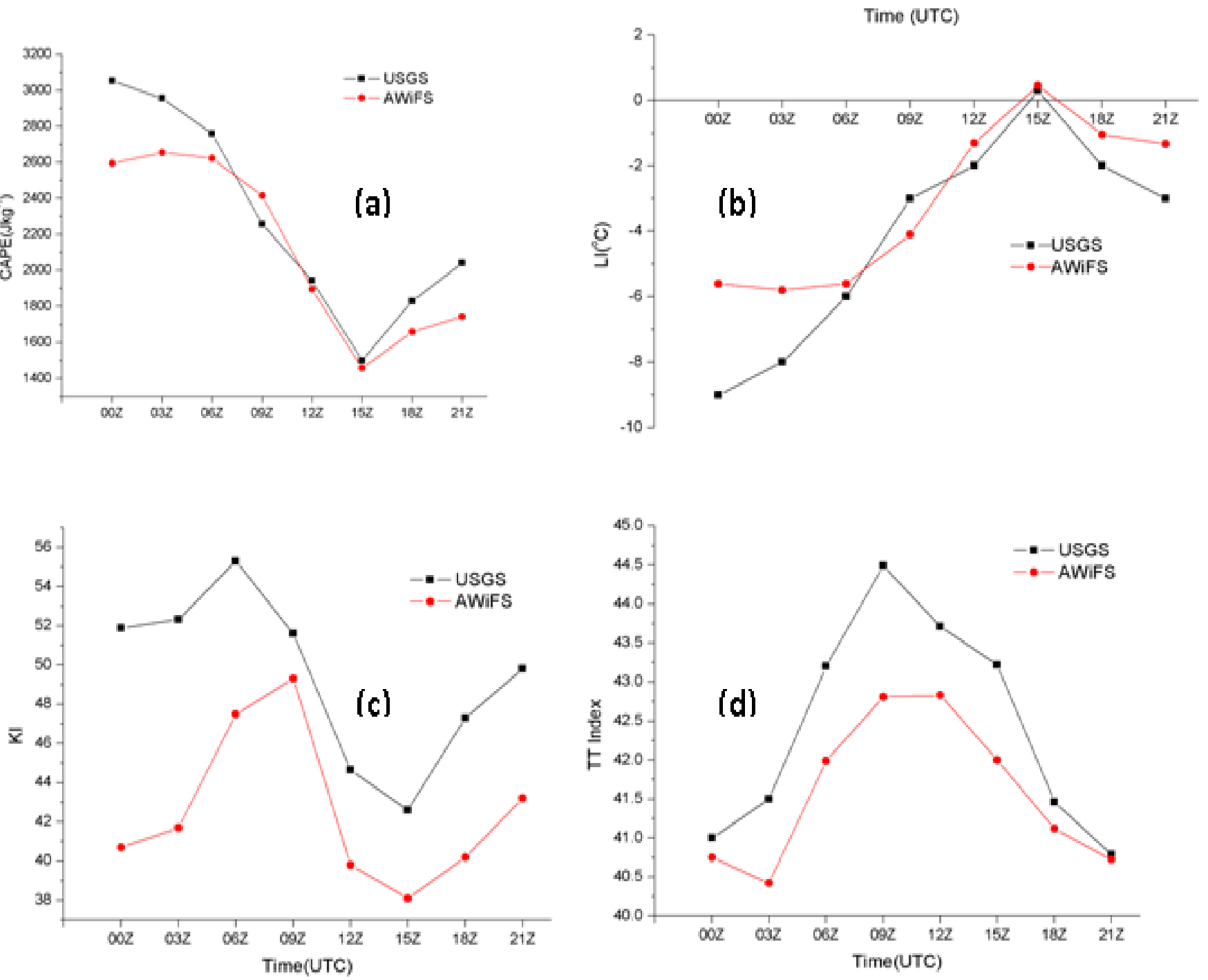

Fig - 5 (a-d): Diurnal variation of (a) CAPE (b) LI (c) K Index (d) Total Totals of Index on $13^{\text {th }}$ April 2006 using MM5 Model. 


\section{April, 2006}
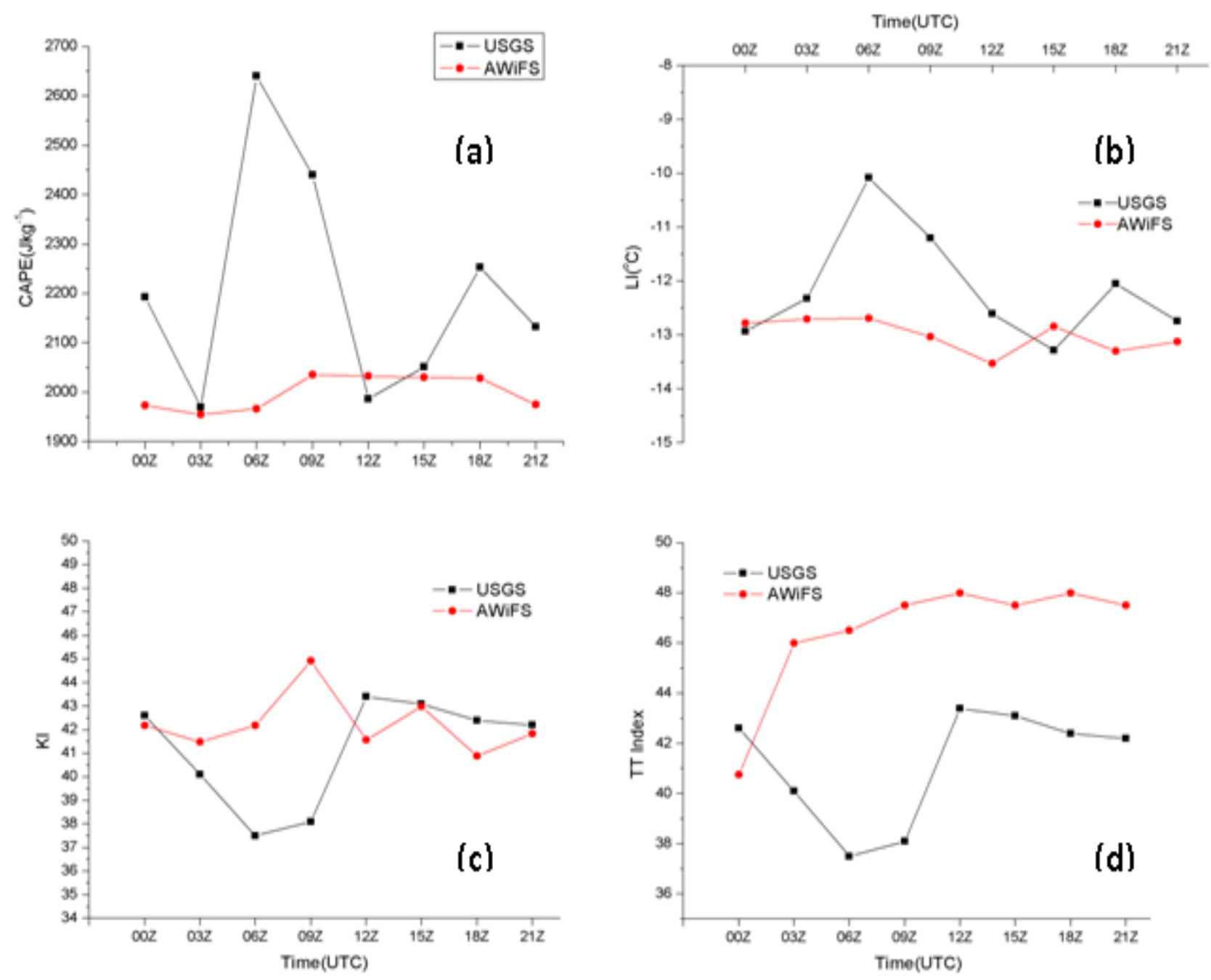

Fig - 6 (a-d): Diurnal variation of (a) CAPE (b) LI (c) K Index (d) Total Totals of Index on $17^{\text {th }}$ April 2006 using MM5 Model.

The MM5 with USGS overestimated rainfall where as MM5 AWiFS is matched well with observed rainfall over Hyderabad (Fig.7 \& 8). The AWiFS LULC data predicted rainfall was $3.59 \mathrm{~mm}$ on 13 April, 2006 while from USGS was $7 \mathrm{~mm}$ (Figs7 b \& c). The actual rainfall from self recording rain gauge which we are operating in the premises of NRSC was $4 \mathrm{~mm}$. Similar trends were observed with model USGS and AWiFS on 17 April, 2006 as shown in Figs8 (a-c).

This suggests that mesoscale model with AWiFS LU/LC data provides better estimates of rainfall which are matching with observed rainfall on both the days. Further, the intensity of the thunderstorm has been analyzed by the analysis of precipitable water as shown in Figs. 9 (a-d). It has been observed that the precipitable water on 13 April, 2006 and 17 April, 2006 storm have different magnitudes at different time intervals. 

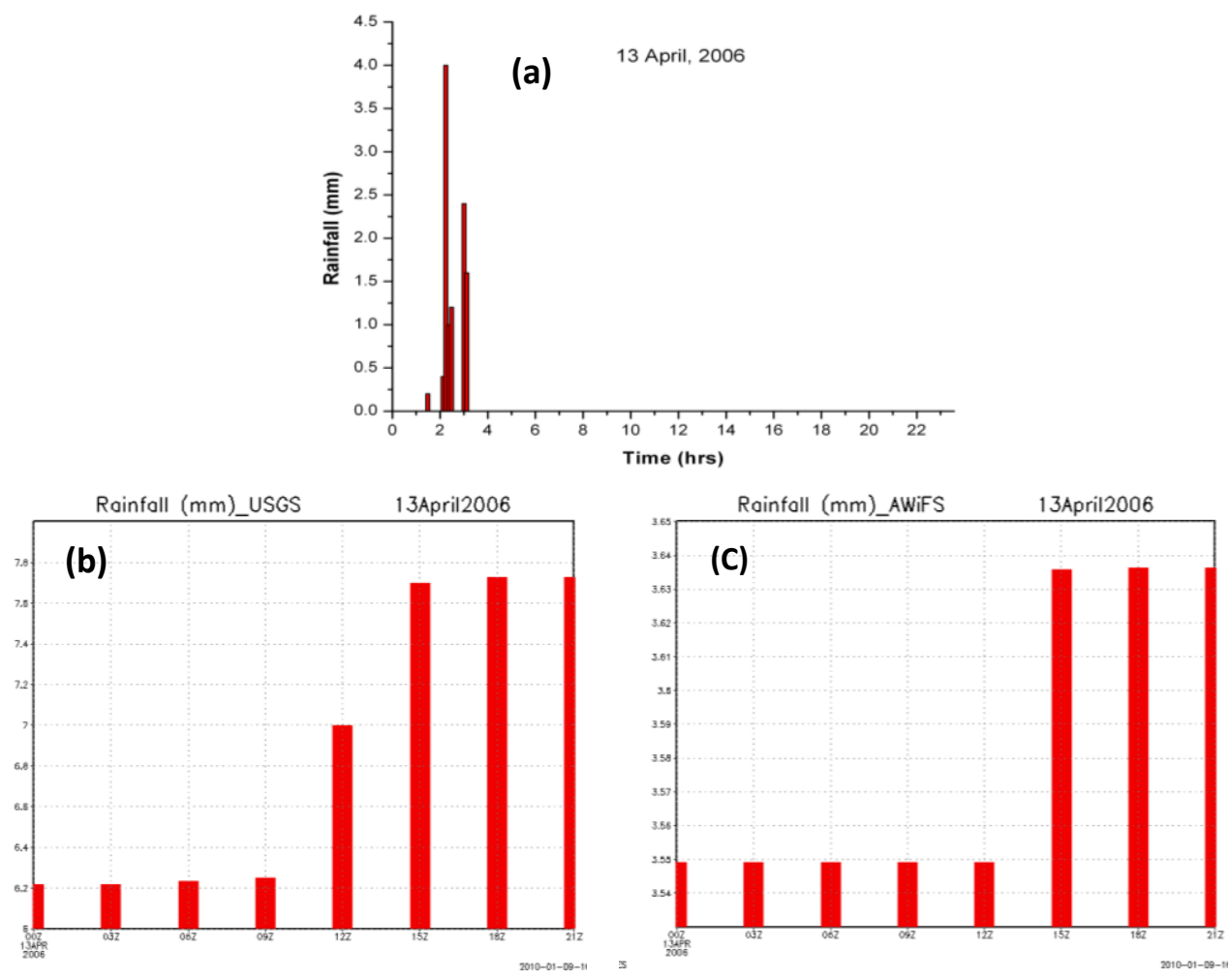

Fig - 7(a-c): Rainfall on $13^{\text {th }}$ April 2006 during 00UTC to 21 UTC (a) IMD (b) MM5 -USGS (c)MM5- AWiFS.
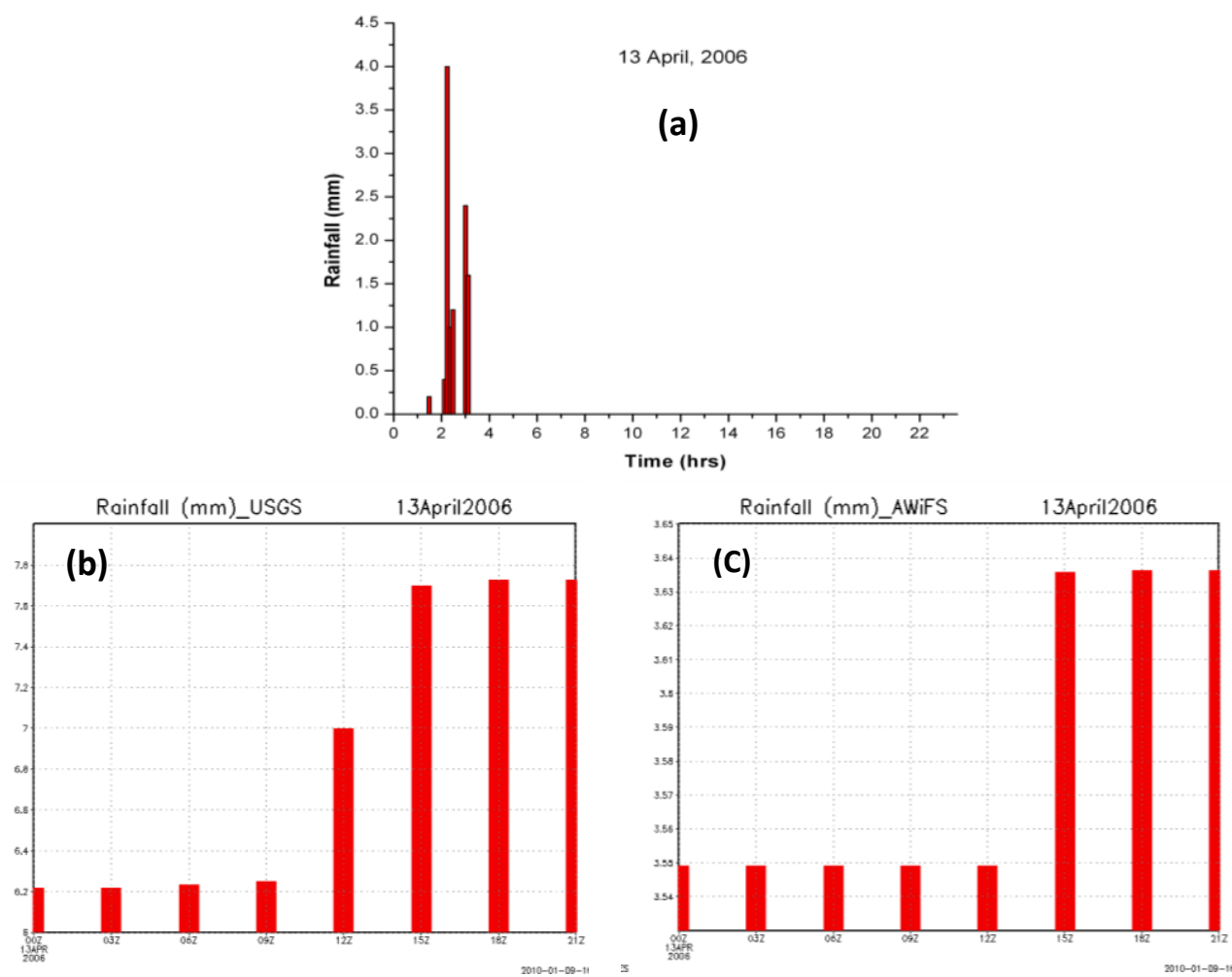

Fig - 8 (a-c): Rainfall on 17 April 2006 during 00UTC to 21 UTC (a) IMD (b) MM5 -USGS (c)MM5- AWiFS. 

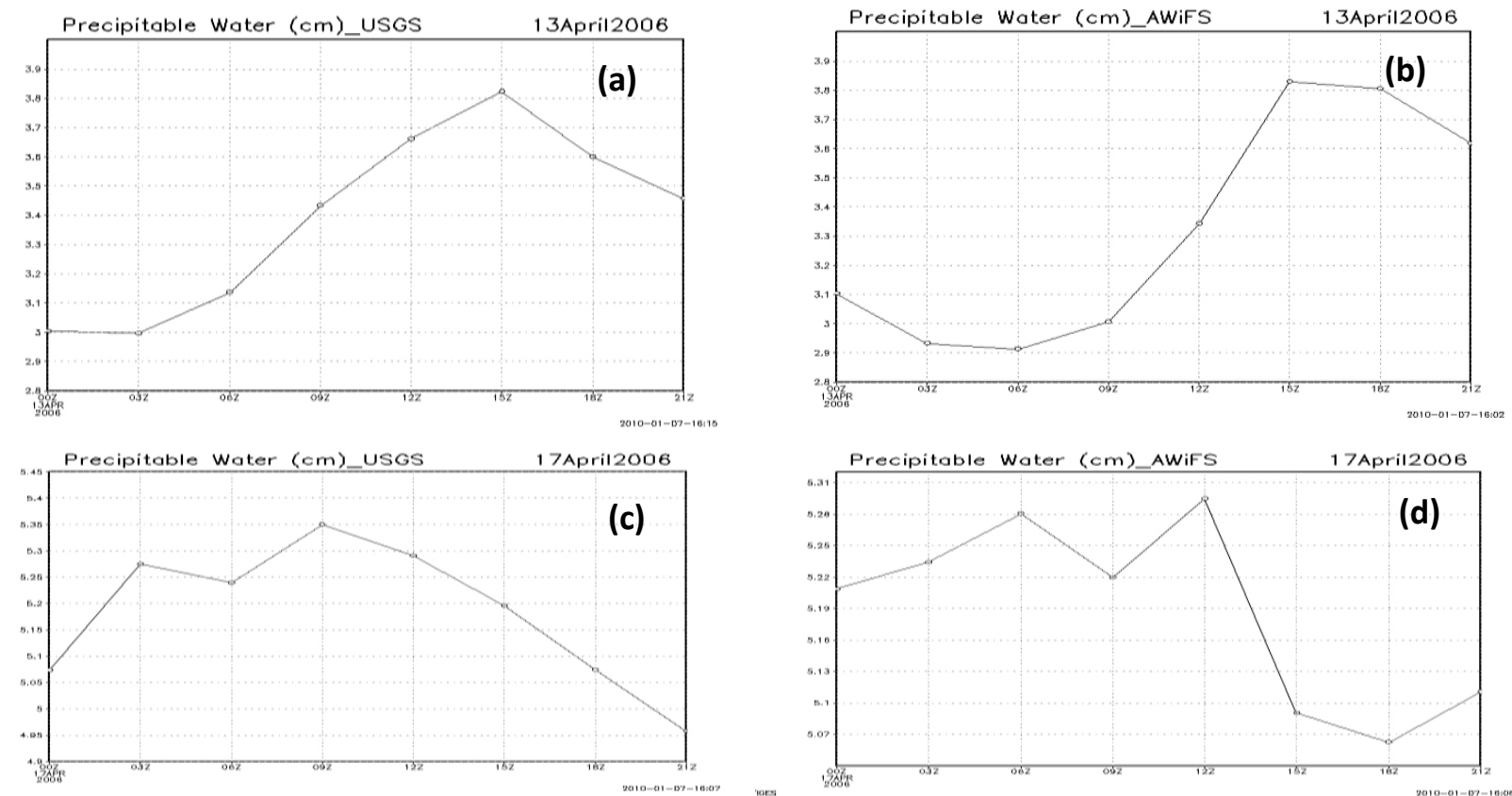

Fig -9 (a-d): Precipitable water (cm) (a,b) USGS and (c,d) AWiFS simulations on $13^{\text {th }}$ and $17^{\text {th }}$ April,2006 during 00UTC to 21 UTC over Hyderabad

\section{CONCLUSIONS}

There is a possibility to incorporate updated LU/LC frequently into the model for reliable predictions. USGS is always predicting rainfall as overestimated. MM5 predictions with updated AWiFS derived LU/LC data could capture stability indices, which act as indicators of severe convective activity compared to USGS LU/LC data. The dynamic and thermodynamic properties of the atmosphere were well simulated by the AWiFS-LU/LC data for the occurrence of thunderstorm over region. Results of this study suggested that incorporation of latest LU/LC data in mesocale models has the potential to provide unique and valuable information for severe thunderstorm forecasts. The results of the study shows the local convective storms were highly sensitive to the triggering mechanism associated with land surface influences.

\section{ACKNOWLEDGEMENTS}

The authors wish to thank Director, Deputy Director, Group Director NRSC for their encouragement and necessary support.

\section{REFERENCES}

[1]. Awedesh, K. (1992). A climatological study of thunderstorm at Lucknow airport, Mausam, 43, 441-444

[2]. Ghosh A., D.Lohar, and J.Das, (2008). Initiation of Nor'wester in relation to mid-upper and low-level water vapor patterns on METEOSAT-5 images Atmospheric Research, Vol.87, no.2,pp.116-135.

[3]. Brooks, H. E., Lee, J. W. and Craven, J. P. (2003). The spatial distribution of severe thunderstorm and tornado environments from global reanalysis data Atmos. Res., (6768), 73-94.

[4]. Craven, J. P., Brooks, H. E. and Hart, J. A. (2002). Baseline climatology of sounding derived parametersassociated with deep, moist convection. 21st Conference on Severe Local Storms, Am. Meteorol. Soc., San Antonio, Tex

[5]. Yamane, Y. and Hayashi, T. (2006). Evaluation of environmental conditions for the formation of severe local storms across the Indian subcontinent. Geophys. Res. Lett., 33, L17806, doi: 10.1029/2006GL026823.

[6]. Braham, R. R. and Wilson, D. (1978). Effects of St. Louis on Convective Cloud Heights, J. Appl. Meteor., 17, 587-592.

[7]. Shepherd, J. M. and Burian, S. J. (2003). Detection of Urban-Induced Rainfall Anomalies in a Major Coastal City, Earth Interactions, 7, 1-17.

[8]. Niyogi, D., Holt, T., Zhong, S., Pyle, P. C., and Basara, J. (2006) Urban and land surface effects on the 30 July 2003 mesoscale convective system event observed in the Southern Great Plains, J.Geophys. Res., 111, D19107, doi: 10.1029/2005JD006746.

[9]. Oke, T. R. (1998). The Urban Energy Balance, Prog. Phys. Geogr., 12, 471-508.

[10]. Gero, A. F. and Pitman, A. J. (2006). The Impact of Land Cover Change on a Simulated Storm Event in the Sydney Basin, J. Appl. Meteor. Climatol. 45, 283-300.

[11]. Tyagi, A. (2007). Thunderstorm climatology over Indian region. Mausam, 58(2), 189-212.

[12]. Lam, J. S. L., Lau, A. K. H. and Fung, J. C. H. (2006). Applications of refined land-use categories for high resolution Mesoscale atmospheric modeling. Boundary Layer Meteorology 119, 263-288. 
[13]. Daewon et al. (2008). Application of high resolution land use and land cover data for atmospheric modeling in the Houston-Galveston metropolitan area, Part II: Air quality simulation results; J. Atmos. Envi., 42, 4853-4869.

[14]. Nicolas Schneider and Werner Eugster. (2004). The impact of Historical Land-Use Changes on the Near-Surface Atmospheric Conditions on the Swiss Plateau, Earth Interactions, Vol8, Pg.12, http://EarthInteractions.org.

[15]. Dudhia. J and J F Bresch. (2002). A Global Version of the PSU NCAR mesoscale model Mon. Weather Rev., 130, 2989-3007.

[16]. Grell, G., Dudhia, J. and Stauffer, D. R. (1994). A descriptin of the fifth-generation Penn State/NCAR Mesoscale Model (MM5). NCAR Technical Note NCAR/TN-398+STR, 117pp

[17]. Rajeevan, M., Bhate, J., Kale, J.D. and Lal, B. (2006) High resolution daily gridded rainfall data for the Indian for the Indian region: analysis of break and active monsoon spells. Curr.sci., 2006, 91, 296-306.

[18]. Badarinath K.V.S., T.R.Kiran Chand and V.Krishna Prasad. (2006). Agriculture Crop Residue Burning in the Indo-Gangetic Plains - A study using IRS-P6 AWiFS satellite data. Current Science, Vol.91, no.8, pp.1065-1068.

[19]. Doswell, C et al. (2006). On the use of the indices and parameters in forecasting severe. Electronic J. Severe Storms Meteo r.1,1-14.

[20]. Johns, R. H. and Doswell, C. A. (1992). Severe local storms forecasting. Weather Forecast, 7, 588-612. 